\title{
Processos cognitivos emergentes de práticas matemáticas mediadas pelo aplicativo GeoGebra: uma investigação com alunos surdos bilíngues do $8^{\circ}$ ano de uma escola pública
}

\author{
Rafael Schilling Fuck - rafaelschillingf@ gmail.com - Universidade do Vale do Rios \\ dos Sinos
}

Resumo: O artigo apresenta uma investigação em desenvolvimento, cujo objetivo principal é compreender como se constituem os processos cognitivos de sujeitos surdos, emergentes de práticas matemáticas mediadas pelo aplicativo GeoGebra. Para atender a esse objetivo, vem sendo realizada uma pesquisa de cunho qualitativo, delineada sob a forma de pesquisa-ação, na qual os participantes são alunos surdos do $8^{\circ}$ ano de uma escola pública e bilíngue, localizada na região metropolitana de Porto Alegre, Rio Grande do Sul. Os conceitos-ferramenta que operam na investigação são: seres-humanos-commídias e políticas cognitivas. Como resultados parciais, observa-se que as práticas desenvolvidas indicam um movimento de superação da recognição ao oportunizar aos sujeitos surdos práticas de experimentação, visualização e problematização.

Palavras-chave: políticas cognitivas; seres-humanos-com-mídias; educação bilíngue de surdos; tecnologias digitais móveis; GeoGebra.

\section{Emergent cognitive processes of mathematical practices mediated by the GeoGebra app: an investigation with deaf bilingual students of the 8th year of a public school}

Abstract: This paper presents a research in development, whose main objective is to understand how the cognitive processes of deaf subjects are constituted in mathematical practices mediated by the GeoGebra app. To reach this objective, a qualitative research has been developed from the perspective of action research, in which the participants are deaf students of the 8th year of a public and bilingual school, located in the metropolitan region of Porto Alegre, Rio Grande do Sul. The tool-concepts that operate in the research are: human-beings-with-media and cognitive policies. As partial results, it is observed that the practices developed indicate a movement to overcome recognition by providing deaf students with practices of experimentation, visualization and problematization.

Keywords: cognitive policies; human-beings-with-media; bilingual education of the deaf; mobile digital technologies; GeoGebra.

\section{Introdução}

Os movimentos da comunidade surda possibilitaram a conquista e a garantia de seus direitos linguísticos, políticos e educacionais, os quais foram obtidos, principalmente, a partir do reconhecimento da Língua Brasileira de Sinais - Libras como língua oficial do Brasil. Esta língua foi reconhecida em 24 de abril de 2002, pela Lei 10.436 (BRASIL, 2002). No entanto, somente em 2005 é que foi regulamentada pelo Decreto 5.626 (BRASIL, 2005), que dispõe, principalmente, sobre as diretrizes para a implementação de processos educacionais de pessoas com surdez na Educação Básica e Ensino Superior.

Decorrente dessa realidade, que é recente, professores e pesquisadores têm se dedicado a discutir e investigar, dentre outras questões, sobre a aprendizagem do sujeito 
surdo em diferentes áreas do conhecimento, particularmente, em Matemática. Embora seja possível observar, atualmente, o desenvolvimento de diversas investigações sobre a aprendizagem de Matemática por esse grupo cultural, seus resultados, ainda, não têm sido suficientes para compreender com mais consistência as singularidades da aprendizagem matemática por alunos surdos, mais especificamente, de seus processos cognitivos.

Nesse contexto, o artigo apresenta uma investigação em desenvolvimento, cujo objetivo principal é compreender como se constituem os processos cognitivos de sujeitos surdos, emergentes de práticas matemáticas mediadas pelo aplicativo GeoGebra. Para atender a esse objetivo, vem sendo realizada uma pesquisa de cunho qualitativo, delineada sob a forma de pesquisa-ação, na qual os participantes são alunos surdos do $8^{\circ}$ ano de uma escola pública e bilíngue, localizada na região metropolitana de Porto Alegre, Rio Grande do Sul.

No intuito de conduzir o leitor a uma compreensão significativa da investigação apresentada neste artigo, propôs-se a estruturá-lo na seguinte forma: inicialmente, apresentam-se os conceitos-ferramenta que fundamentam a pesquisa realizada. Em seguida, descreve-se o método. Após, são descritas e analisadas algumas das práticas desenvolvidas com os sujeitos participantes. Por fim, tecem-se as considerações finais, seguidas das referências.

\section{Conceitos-ferramenta}

Nesse momento, discutem-se os conceitos-ferramenta que operam nesta investigação em andamento, os quais dão conta de descrever e analisar o objeto da pesquisa. Tais conceitos, que se referem à epistemologia e aprendizagem, são, a saber: seres-humanos-com-mídias (BORBA; VILLARREAL, 2005) e cognição inventiva (KASTRUP, 2007).

Borba e Villarreal (2005) apresentam o construto teórico seres-humanos-commídias, por meio do qual defendem que a produção de conhecimento é realizada por coletivos constituídos por atores humanos e não humanos. Para desenvolvê-lo, apoiaramse nos estudos de Lévy (1993, 1999), de Tikhomirov (1981) e de Borba (1995, 1999, 2006). A partir destes estudos, Borba e Villarreal (2005) argumentam que coletivos constituídos por seres-humanos-com-mídias devem ser vistos como a unidade básica que produz conhecimento. Para os pesquisadores, o processo de construção do conhecimento pode ser considerado social não apenas na perspectiva de envolver mais do que um humano, mas sim pelo entendimento de que esse processo é condicionado pelas tecnologias da inteligência. Desse modo, pode-se afirmar que a escrita, a oralidade e as tecnologias informáticas são, também, coparticipantes na produção de conhecimento.

Para uma melhor compreensão desta concepção epistemológica, recorre-se a Tikhomirov (1981), o qual apresenta três teorias que auxiliam na compreensão de como as Tecnologias Digitais (TD) afetam a cognição humana e, consequentemente, como estas podem afetar a Educação, particularmente, a Educação Bilíngue para Surdos. Embora este autor tenha desenvolvido teorias a partir do computador, suas contribuições podem ser estendidas, também, para as TD. A primeira teoria que propõe é a da substituição, na qual o computador é concebido como substituto do ser humano. O argumento favorável a esta teoria é o de que o computador consegue estabelecer os mesmos resultados que os seres humanos em determinadas tarefas, e, portanto, pode substituí-los.

A segunda é a da suplementação, na qual o computador complementa o ser humano, isto é, a máquina resolve os problemas que lhes são considerados "difíceis" ou 
demorados. Tikhomirov afirma que esta visão é baseada na teoria da informação, a qual defende que o pensamento pode ser fragmentado em pequenas partes. Essa teoria é criticada, pois "tem uma visão apenas quantitativa e não qualitativa do pensamento" (BORBA, 1999, p. 287). Em decorrência dessa perspectiva teórica, há uma dicotomia entre ser humano e tecnologia e, portanto, não há interação entre tecnologia e cognição. Por fim, a terceira teoria, a da reorganização, defende que o computador reorganiza o pensamento, proporcionando novas possibilidades à atividade humana, como feedbacks a passos intermediários de determinadas atividades.

Em cada período da história, o conhecimento humano foi condicionado, de acordo com Lévy (1993), pelas tecnologias da inteligência - oralidade, escrita e informática que estão relacionadas com a memória e o conhecimento.

As primeiras sociedades se estruturavam pela oralidade, a qual era utilizada para estender a memória humana. Nesse sentido, pode-se compreender a importância dos mitos para as sociedades orais, pois eram a forma de manter vivas e guardar as partes de sua cultura. Nessas sociedades, "quase todo o edifício cultural está fundado sobre as lembranças dos indivíduos. A inteligência, nestas sociedades, encontra-se muitas vezes identificada com a memória, sobretudo com a auditiva" (LÉVY, 1993, p. 77).

A escrita materializada em livros, semelhantes aos quais se tem acesso hoje, é que permite que a memória seja estendida de modo qualitativamente diferente em relação à oralidade. A escrita surgiu da necessidade de registrar e difundir os conhecimentos, pois a oralidade já não atendia mais as necessidades de comunicação humana. Com o advento da escrita, emerge a linearidade do pensamento e a separação física entre narrador e ouvinte, já que o texto pode ser lido em qualquer espaço e tempo, o que possibilitou a prática de interpretação.

Analogamente às tecnologias supracitadas, a informática, também, representa uma nova extensão de memória. Entretanto, essa extensão apresenta diferenças qualitativas em relação à oralidade e à escrita. Uma delas se refere ao aspecto de que essa tecnologia permite que o pensamento linear seja desafiado pelos modos de pensar constituídos pela simulação, experimentação e linguagem obtida da fusão entre escrita, oralidade, imagens e comunicação instantânea.

Para os sujeitos ouvintes, a fala e a escrita são extensões da memória, do mesmo modo que a língua de sinais e registros visuais são extensões da memória dos sujeitos surdos. Com o advento do computador pessoal, o conhecimento passa a ser mais difundido e todos podem ter acesso à informação de acordo com suas necessidades. Desse modo, a integração do computador às tecnologias da oralidade e da língua de sinais promovem a emergência de novos conhecimentos (CAPPELIN; GRECA; BALBINO, 2015).

Em síntese, a perspectiva epistemológica seres-humanos-com-mídias coloca em destaque o papel das mídias no processo de produção do conhecimento, evidenciando que as mídias moldam a maneira como o sujeito pensa, do mesmo modo que são moldadas por este mesmo sujeito. Isso, pois "os seres humanos são constituídos por técnicas que estendem e modificam seu raciocínio e, ao mesmo tempo, esses seres humanos estão constantemente transformando essas técnicas" (BORBA; PENTEADO, 2005, p. 46).

Esta perspectiva epistemológica contribui para compreender que a produção do conhecimento está condicionada pelo coletivo seres-humanos-com-tecnologias, no caso desta investigação, seres-humanos-surdos-com-tecnologias, colocando em ênfase na interrelação entre sujeitos e tecnologias. No entanto, tal perspectiva apresenta um limite no que se refere à concepção cognitiva dos sujeitos. Entende-se que esse tipo de 
concepção determina o modo de como as tecnologias são utilizadas para a produção do conhecimento, podendo restringir-se a pelo menos duas finalidades: representação ou invenção do conhecimento. Essa problematização está associada à política cognitiva, termo definido por Kastrup $(2005,2007,2008)$ e pauta-se na distinção entre diferentes concepções de cognição.

O cognitivismo computacional defende que conhecer significa processar informações oriundas do meio (inputs), produzindo respostas adequadas (outputs). Nessa perspectiva, a cognição é definida como computação simbólica mediada por regras lógicas, cujo objetivo é a representação adequada do mundo. Seus pressupostos dão sustentação a um movimento que pressupõe sujeito e objeto como polos dados a priori do processo de conhecer.

No paradigma do cognitivismo, a Matemática é concebida como prévia à existência humana. Quando organizada em um saber escolarizado, determina seus objetos como dados a serem descobertos em sala de aula, pressupondo, também, a existência de um sujeito humano entendido como interioridade, o que significa que representa em si aquilo que lhe é exterior, isto é, os objetos matemáticos. Nesse sentido, a aprendizagem consiste em adequar-se do modo mais perfeito possível àqueles objetos, assumindo-se como um processo de adaptação ao mundo através de sua representação (CAMMAROTA; CLARETO, 2012).

Configura-se, assim, uma atenção seletiva, orientada no sentido de uma ação eficaz, isto é, a aprendizagem do objeto. É exigida do sujeito aprendente a capacidade de memorização que dê conta de reconstituir o objeto exatamente como ele é. Ainda, exigese uma linguagem desprovida de inconsistências e incoerências que expresse, rigorosamente, em texto aquilo que o objeto formal já assumia. Em síntese, nesse paradigma, a aprendizagem da Matemática se dá por meio da recognição, que produz imagens de pensamento, as mais fidedignas quanto possível do objeto mesmo da Matemática.

Em oposição ao cognitivismo computacional que concebe o conhecimento como representação do mundo através do processamento de informações por leis e regras lógicas, a cognição inventiva entende o conhecimento como uma produção coengendrada do sujeito e do mundo. O conceito de cognição inventiva, proposto por Kastrup (2007), sustenta-se nos estudos de Maturana e Varela, desde o conceito de autopoiese ao de enação. A pesquisadora opera uma ampliação desse conceito, propondoo como uma cognição aberta à inventividade e à variação, cujos processos levam a resultados que não podem ser antecipados. Assim, para ela, as noções de sujeito e objeto como polos se desfazem pois, sujeito e objeto são efeitos da ação cognitiva, isto é, são coengendrados e produzem-se mutuamente. Logo, a ação cognitiva não é pautada no sujeito ou numa determinação do ambiente sobre o homem.

O significado de invenção que se assume neste artigo é o de diferenciação de si. A invenção se configura quando a cognição sofre transformações em sua essência para outra, diferenciando-se de si mesma, em uma diferença que, na perspectiva bergsoniana, é de natureza e não de grau. Em uma abordagem de diferença de grau, concebe-se que a aprendizagem se dá pela aquisição de mais conhecimento, o que determina uma visão recognitivista, pois somente se acumula graus sem a produção de uma cognição original.

Nesse sentido, percebe-se a relevância dos breakdowns, rupturas no processo de recognição fundamentais para transformar a cognição de recognitiva em inventiva. São nesses breakdowns que emerge a invenção de problemas, pois a ruptura consiste na própria problematização da cognição. Portanto, não há sentido em pensar em uma 
adaptação ao meio, pois, como se enfatizou anteriormente, a cognição se diferencia de si mesma e é nesse processo de diferenciação que há invenção e não criatividade, pois esta se encontra condicionada aos limites decorrentes de uma adaptação ao meio.

A partir do exposto, Kastrup (2007) salienta duas possibilidades de se relacionar com a aprendizagem. Na primeira, aprende-se para adquirir um saber. Pressupõe-se sujeito e objeto como polos distintos e prévios ao processo de conhecer, o que confere à cognição como processamento de dados e solução de problemas. A política que se configura, desse modo, é a da representação (ou recognição), na qual os sujeitos são estimulados a se apropriar de modelos e modos de resolução de problemas transmitidos por seus professores. A segunda possibilidade é a política da invenção, na qual aprendese a aprender para continuar aprendendo e inventando a si mesmo e ao mundo. A aprendizagem inclui a experiência da problematização e invenção de problemas. Sujeito e objeto são concebidos como efeitos da prática cognitiva. Nesta perspectiva, conhecer não significa apenas representar, mas criar e produzir realidade. A produção de aprendizagem inventiva inclui a recognição como ferramenta.

Em síntese, apresentou-se neste tópico os pressupostos da epistemologia sereshumanos-com-mídias, a qual sustenta que a produção do conhecimento se dá na interação entre humanos e tecnologias e que estas reorganizam o pensamento e, ao mesmo tempo, são moldadas por esses primeiros. No entanto, considera-se que, nessa epistemologia, estão presentes políticas cognitivas, as quais orientam o modo de se relacionar com o conhecimento, as tecnologias, o mundo e consigo mesmo. Nesse sentido, recorreu-se ao conceito de políticas cognitivas para problematizar e ampliar a compreensão sobre a epistemologia seres-humanos-com-mídias e os processos cognitivos que se constituem na interação entre sujeitos e tecnologias. Essa discussão possibilitou definir os conceitosferramenta para analisar e problematizar os processos cognitivos que emergem no coletivo seres-humanos-surdos-com-tecnologias-digitais, na perspectiva da cognição inventiva, que é o objetivo principal da pesquisa descrita neste artigo.

\section{Método}

A pesquisa desenvolvida assume características de uma investigação qualitativa (LÜDKE; ANDRÉ, 1986; BOGDAN; BIKLEN, 1994), pois busca a compreensão de um determinado problema, isto é, como se constituem os processos cognitivos emergentes do coletivo seres-humanos-surdos-com-tecnologias-digitais. Decorrente da perspectiva do método qualitativo, elegeu-se a pesquisa-ação (THIOLLENT, 2003) para desenvolver o estudo.

Os sujeitos participantes da pesquisa são 7 alunos surdos do $8^{\circ}$ ano de uma escola pública bilíngue, localizada na região metropolitana de Porto Alegre, Rio Grande do Sul. A faixa etária desses sujeitos está situada entre 14 e 35 anos e, salienta-se que o autor responsável pela pesquisa apresentada neste artigo é, também, o professor de Matemática desses sujeitos.

Para a produção dos dados, recorreu-se aos seguintes instrumentos: materiais produzidos pelos alunos, registros em diário de campo, registros fotográficos e de vídeo e entrevistas individuais. Esses instrumentos foram utilizados no contexto de uma Unidade de Aprendizagem criada para desenvolver atividades de Matemática mediadas pelo software GeoGebra. De acordo com Hillesheim (2006, p. 31), a UA "é um conjunto de atividades escolhidas para trabalhar um tema, envolvendo conteúdos, habilidades e atitudes que são integrados e organizados com a intenção de proporcionar aprendizagem 
significativa". Nesse sentido, uma UA consiste em um conjunto de atividades elaboradas, estrategicamente, com a intenção de promover processos de reconstrução de conceitos pelos alunos.

As atividades que constituem a UA foram planejadas sob a perspectiva da cognição inventiva, de modo que possibilitassem aos alunos não somente a representação dos objetos matemáticos por meio do GeoGebra, mas sim sua problematização e levantamento de questões relevantes a partir da interação com seus colegas, professor e tecnologia digital em questão. Ainda, buscou-se, também, conferir flexibilidade à estrutura das atividades para que não limitassem as interações dos alunos, isto é, para que pudessem dar aos sujeitos maior liberdade de interação, expressão de seus pensamentos e de problematização, os quais são elementos fundamentais para o desenvolvimento de uma aprendizagem inventiva.

\section{Descrição e Análise}

As atividades da UA estão sendo desenvolvidas desde o final do mês de agosto e pretende-se concluí-las em dezembro deste ano. Para realizá-las, vem-se disponibilizando duas horas-aula, semanalmente, na disciplina de Matemática, ministrada pelo professorpesquisador e autor deste artigo. Nesse momento, serão descritas e apresentadas análises parciais de três atividades mediadas pelo GeoGebra, as quais abordam conteúdos de Matemática previstos pelo Plano de Estudos da escola em que estudam os sujeitos surdos, participantes da pesquisa.

Ressalta-se que, inicialmente, foi solicitado aos alunos que realizassem o download do aplicativo GeoGebra em seus smartphones. Apenas dois alunos não puderam fazê-lo, pois um deles não possui celular e outro não conseguiu baixá-lo devido a restrições técnicas de seu aparelho. Nesse caso, foi-lhes emprestado um tablet para realizar as atividades em dupla. Os alunos demonstraram interesse em baixar o aplicativo, fazendo-o rapidamente. Considera-se que esse interesse ocorreu devido à oportunidade em realizar atividades com seu celular, que é um recurso muito utilizado em seu cotidiano e com o qual estão familiarizados. Ainda, observa-se que os alunos possuem curiosidade em experimentar aplicativos ou recursos diferentes de seu celular. Essa observação foi fundamental para que o professor planejasse as atividades da UA e selecionasse o aplicativo GeoGebra, visando atender aos objetivos de aprendizagem dos alunos.

Após o download do aplicativo, os alunos tiveram um momento de exploração dos recursos disponíveis pelo Geogebra, no qual o professor lhes explicou seu objetivo e a função de algumas de suas ferramentas, tais como Ponto, Segmento, Polígono, Perímetro, Comprimento e Área. A explicação de cada uma dessas ferramentas básicas ocorreu no seguinte modo: inicialmente, foi apresentada a ferramenta Ponto com alguns exemplos e, em seguida, solicitou-se aos alunos que marcassem 4 pontos na área de trabalho do aplicativo. A partir dessa atividade, os sujeitos foram desafiados a tentar encontrar a ferramenta que lhes permite traçar um segmento entre os pontos e, desse modo, formar uma figura geométrica ${ }^{1}$. Alguns alunos obtiveram êxito nessa tarefa. Após, o professor lhes explicou o uso das ferramentas de comprimento, perímetro e área.

Nessa atividade, predominou a perspectiva recognitiva, pois o professor assumiu a tarefa de transmitir informações sobre o GeoGebra e de instruir os alunos sobre algumas de suas ferramentas. Assim, os alunos desempenharam uma prática de reprodução das

\footnotetext{
${ }^{1}$ Salienta-se que os alunos já estudaram alguns conceitos básicos de geometria.
} 
ações do professor no aplicativo, isto é, o professor lhes orientava, por exemplo, como construir um retângulo e, em seguida, os alunos o reproduziam em seu aplicativo. Foi necessário, nesse momento, desenvolver uma prática recognitiva para que os alunos pudessem se apropriar das ferramentas básicas do GeoGebra, as quais seriam demandadas em atividades posteriores, possibilitando-lhes a problematização de sua cognição e, consequentemente, invenção de problemas. Desse modo, compreende-se que práticas recognitivas são necessárias para o desenvolvimento da aprendizagem inventiva, ou seja, a cognição inventiva inclui a recognição como ferramenta. Ainda, em outras palavras, a invenção surge de base recognitiva (KASTRUP, 2007).

Outra atividade proposta aos alunos foi a construção de triângulos escaleno, isósceles e equilátero, com medidas dos lados de sua escolha. Para o desenvolvimento desta atividade, os alunos já possuíam conhecimentos prévios sobre o conceito e propriedades de cada um desse tipo de triângulo, além de seus sinais em Libras, combinados durante a aula. Para atender ao objetivo dessa tarefa, os alunos recorreram à ferramenta Polígono e construíram, sem dificuldades, os triângulos escaleno e isósceles. Entretanto, apresentaram dificuldades em construir um triângulo equilátero, pois a ferramenta selecionada não lhes permitia construí-lo, de modo que todos seus lados apresentassem a mesma medida.

Nesse momento, então, fez-se necessária a intervenção do professor para problematizar essa dificuldade. Essa atitude de problematizar junto aos alunos é pertinente, uma vez que os sujeitos da investigação apresentam dificuldades em elaborar perguntas relevantes sobre o objeto de estudo. Eles estão habituados a práticas de repetição e, portanto, a uma aprendizagem recognitiva. Desse modo, o papel do professor é fundamental para conduzí-los a provocar "rachaduras" em sua cognição para que possam aprender inventivamente. Após esse momento de problematização, foi-lhes sugerido o uso da ferramenta Polígono Regular para a construção de um triângulo equilátero. Ao inserir dois pontos na área de trabalho do GeoGebra e escrever o número de vértices do polígono desejado, este recurso permite a construção de polígonos regulares cujas medidas de seus lados são iguais.

Destaca-se, também, a atividade de encontrar, utilizando o GeoGebra, a medida dos lados de um retângulo, dadas as suas medidas de área e perímetro. Ou, ainda, encontrar as medidas de uma grandeza, dados área/perímetro e medida de um dos lados. Essa atividade foi organizada em forma de tabela (Figura 1) para que as informações pudessem ser visualizadas e compreendidas mais facilmente. Isso, pois alguns dos alunos surdos, participantes desta investigação, apresentam dificuldades em ler e compreender enunciados em Língua Portuguesa escrita.

Figura 1 - Atividade com tabela

\begin{tabular}{|c|c|c|c|c|}
\hline RETÂNGULO & PERÍMETRO & ÁREA & BASE & ALTURA \\
\hline A & 16 & & 3 & \\
\hline B & 18 & 20 & & \\
\hline C & & 8 & & 4 \\
\hline D & & & 5 & 5 \\
\hline E & 26 & & & 6 \\
\hline F & & & 2 & 6 \\
\hline
\end{tabular}

Fonte: o autor

Para realizar essa atividade, os alunos construíram cada retângulo da tabela no aplicativo, utilizando, primeiramente, a ferramenta Polígono e, em seguida, recorreram 
às ferramentas Distância, Comprimento ou Perímetro e Área para definir as medidas de seus lados e grandezas (Figura 2).

Figura 2 - Retângulo construído no aplicativo GeoGebra

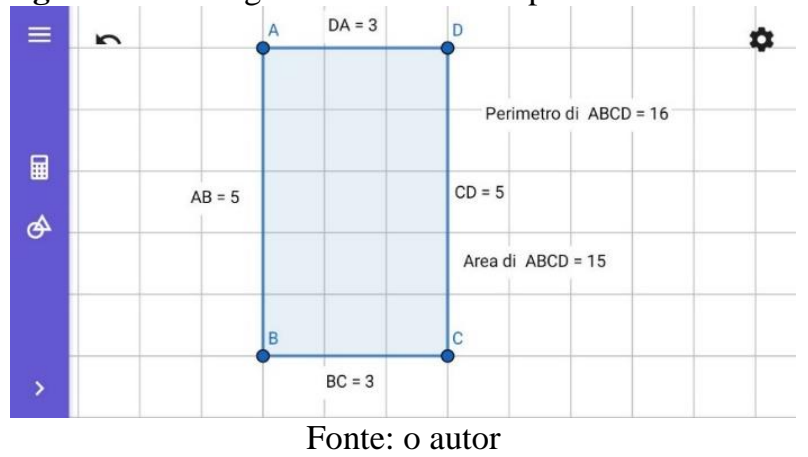

Após esse procedimento, os alunos obtiveram como produto um retângulo experimental digital, isto é, um retângulo para realizar o experimento de encontrar as medidas de seus lados, perímetro e área por meio da manipulação de suas dimensões. Desse modo, não era necessário construir um novo retângulo para realizar cada atividade, pois bastava, utilizando o mesmo retângulo e com o toque na tela do smartphone/tablet, arrastar seus segmentos de comprimento e altura, diminuindo ou aumentando suas medidas. Esse procedimento possibilitou aos sujeitos interagir com o retângulo experimental, manipulando-o para encontrar os valores das medidas que determinam as grandezas dadas ou vice-versa. Ainda, essa prática lhes oportunizou ir além da visualização estática, na qual o sujeito apenas visualiza uma imagem e busca desenvolver interpretações sobre, sem interagir com ela e manipulá-la de acordo com seu interesse e conhecimentos prévios.

Desse modo, considera-se que essa atividade oportunizou aos sujeitos um papel mais ativo, já que puderam desenvolver práticas experimentais ao manipular as dimensões do retângulo e, também, práticas visuais de interpretação na tentativa de encontrar relações entre as medidas dos lados de um retângulo e medidas de sua área e perímetro. Durante o desenvolvimento dessa atividade, dois alunos construíram, inicialmente, apenas alguns retângulos e, logo após, completaram a tabela sem precisar manipular outros, o que evidencia a compreensão da relação entre medidas dos lados e medidas das grandezas. Os outros alunos completaram a tabela com o apoio do retângulo experimental.

Esse tipo de atividade, em que o aluno necessita participar ativamente, realizando práticas de experimentação e visualização em Matemática, contribui-lhe para tomar consciência de suas ações, pensamento e aprendizagem. Nesse sentido, quando o aluno percebe a si mesmo e tem a oportunidade de assumir sua própria aprendizagem, há mais possibilidades de problematizá-la e levantar questões pertinentes, o que é essencial para o desenvolvimento de uma aprendizagem inventiva. $\mathrm{O}$ aluno que não é conduzido a práticas de experimentação e problematização apenas tem a possibilidade de representar o conhecimento transmitido pelo professor e, desse modo, continuar perpetuando uma visão de mundo recognitiva.

Em síntese, as atividades descritas e analisadas acima evidenciam, de um modo geral, que as práticas produzidas no interior do coletivo seres-humanos-surdos-comGeoGebra indicam um movimento de superação da recognição ao oportunizar aos sujeitos surdos a interagir e produzir conhecimento de Matemática, utilizando tecnologias digitais móveis (smartphones, tablet e aplicativo de geometria dinâmica). Salienta-se, 
ainda, que propostas de atividades que possibilitam ao aluno práticas de experimentação, visualização e manipulação podem proporcionar a criação de ambientes de aprendizagem inventiva pautados na problematização.

\section{Considerações Finais}

O artigo descreveu parte de uma investigação em fase inicial de desenvolvimento, cujo objetivo principal é compreender os processos cognitivos de sujeitos surdos bilíngues, emergentes de uma Unidade de Aprendizagem (UA) de Matemática mediada pelo aplicativo GeoGebra.

Ressalta-se que a relevância do desenvolvimento dessa investigação não é apenas oportunizar experiências de invenção por meio de Tecnologias Digitais aos sujeitos surdos, mas, também, de valorização de sua cultura. No entanto, considera-se que as práticas de aprendizagem inventiva possibilitam a emergência de elementos próprios da cultura surda, enquanto que, nas recognitivas, não há espaço para sua expressão. Nessas práticas recognitivas, os processos cognitivos são apenas representações do mundo e não há neles elementos próprios da cultura surda, uma vez que o sujeito surdo apenas reproduz conhecimentos, conhecimentos estes oriundos de uma cultura ouvinte.

Para finalizar, as práticas desenvolvidas no interior do coletivo seres-humanossurdos-com-GeoGebra indicam um movimento de superação da recognição ao oportunizar aos sujeitos surdos práticas de experimentação, visualização e problematização, favorecendo, assim, a criação de ambientes de aprendizagem inventiva.

\section{Referência}

BOGDAN, R; BIKLEN, S. Investigação qualitativa em educação: uma introdução à teoria e aos métodos. Porto: Porto Editora, 1994.

BORBA, M. C. Teaching Mathematics: computers in the classroom. The Clearing House, Washington, v. 68, n. 6, p.333-334, jul. 1995.

- Tecnologias informáticas na Educação Matemática e reorganização do pensamento. In: BICUDO, M. A. V. (org.). Pesquisa em Educação Matemática: concepções e perspectivas. São Paulo: UNESP, 1999.

Humans with Media: a performance collective in the classroom? Keynote Address at the Fields Symposium on Digital Mathematical Performance, June 2006. Disponível em <http://www.edu.uwo.ca/dmp/>. Acesso em: 20 ago. 2008.

BORBA, M. C; PENTEADO, M. G. Informática e Educação Matemática. Belo Horizonte: Autêntica, 2005.

BORBA, M.C; VILLARREAL, M. E. Humans-with-media and the reorganization of mathematical thinking: information and communication technologies, modeling, visualization and experimentation. New York, NY: Springer, 2005.

BRASIL. Decreto n. 5.626, de 22 de dezembro de 2005. Regulamenta a Lei n. 10.436, de 24 de abril de 2002, que dispõe sobre a Língua Brasileira de Sinais - Libras, e o art. 18 da 
Lei no 10.098, de 19 de dezembro de 2000. Brasília, DF: Presidência da República; Casa Civil, 2005. Disponível em: <http://www.planalto.gov.br/ccivil_03/_ato20042006/2005/decreto/D5626.htm>. Acesso em: 08 out. 2016.

BRASIL. Lei n. 10.436, de 24 de abril de 2002. Dispõe sobre a Língua Brasileira de Sinais. Brasília, DF: Presidência da República; Casa Civil, 2002. Disponível em: <http://www.planalto.gov.br/ccivil_03/Leis/2002/ L10436.htm>. Acesso em: 08 set. 2016.

CAMMAROTA, G.; CLARETO, S. M. A cognição em questão: invenção, aprendizagem e Educação Matemática. Práxis Educativa, Ponta Grossa, v. 7, n. 2, p. 585-602, jul./dez.2012.

CAPPELIN, A; GRECA, L. M; BALBINO, R. O uso de recursos tecnológicos na alfabetização matemática das crianças surdas. Revista Espaço, n. 43, jan./jun. 2015. p. 167-197.

HILLESHEIM, R. A viabilidade do educar pela pesquisa a partir de uma Unidade de Aprendizagem sobre serpentes. 2006. Dissertação (Mestrado em Educação em Ciências e Matemática) - Faculdade de Física, Programa de Pós-graduação em Educação em Ciências e Matemática, Pontifícia Universidade Católica do Rio Grande do Sul - PUCRS, Porto Alegre, 2006.

KASTRUP, V. Políticas cognitivas na formação do professor e o problema do devirmestre. Revista Educação e Sociedade, Campinas, vol. 26, n. 93, p. 1273-1288. 2005.

A invenção de si e do mundo: uma introdução do tempo e do coletivo no estudo da cognição. Belo Horizonte: Autêntica, 2007.

Cognição contemporânea e a aprendizagem inventiva. In: KASTRUP, V; TEDESCO, S; PASSOS, E. Políticas da cognição. Porto Alegre: Sulina, 2008.

LÉVY, P. As tecnologias da inteligência: o futuro do pensamento na era da informática. Rio de Janeiro: Editora 34, 1993.

Cibercultura. São Paulo: Ed.34, 1999.

LÜDKE, M.; ANDRÉ, M. Pesquisa em educação: abordagens qualitativas. São Paulo: EPU, 1986.

THIOLlENT, Michel. Metodologia da Pesquisa-Ação. São Paulo: Cortez, 2003.

TIKHOMIROV, O. K. The psychological consequences of computarization. In: WERTSCH, J. V. (Ed.). The Concept of Activity in Soviet Psychology. New York: M. E. Sharpe Inc., 1981, p. 256- 278. 